\title{
Mielose eritrêmica em um gato
}

\author{
Erythremic myelosis in a cat
}

\section{Danieli Brolo Martins, ${ }^{\mathrm{I}, I^{*}}$ Marina Gabriela Carvalho Mori Cunha ${ }^{\mathrm{I}}$ Eduardo Keinji Masuda Sonia Terezinha dos Anjos Lopes ${ }^{\text {III }}$ Cinthia Melazzo MazzantiII Ney Luiz Pippi ${ }^{\text {III }}$ Rafael Almeida Fighera ${ }^{\text {IV }}$}

\section{- NOTA -}

\section{RESUMO}

Neste relato, é descrito um caso de mielose eritrêmica em um gato. Essa doença é considerada de aparecimento raro na clínica médica veterinária. Uma gata, raça Siamês, de um ano de idade, foi atendida com sinais clínicos de acentuada anemia, emaciação e febre. Havia marcada anemia arregenerativa, com grande número de precursores eritróides e megaloblastos atípicos, identificados pelo hemograma. O mielograma revelou população eritrocitária acima de $85 \%$, quando comparada com a mielóide. A citologia aspirativa por agulha fina dos linfonodos revelou a presença de células eritróides imaturas. Na necropsia, o baço, os linfonodos e a medula óssea estavam obliterados por células neoplásicas. O diagnóstico de mielose eritrêmica foi dado com base nos achados clínico-laboratoriais $e$ anatomopatológicos.

Palavras-chave: leucemia, síndrome de DiGuglielmo, anemia, mielograma, citologia aspirativa por agulha fina.

\section{ABSTRACT}

The aim of this research is to describe a case of erythremic myelosis in a cat. This disease is considered rare in veterinary clinics. A one-year-old female siamese cat was brought to the veterinary hospital with clinical signs of severe anemia, emaciation and fever. The blood panel revealed marked nonregenerative anemia with elevated number of atypical erythroid progenitors and megacaryoblasts. Elevated atypical erythroid over myeloid precursors (above 85\%) were also found in bone marrow biopsy. Fine-needle aspiration cytology of lymph nodes revealed immature erythoid cells. At necropsy, spleen, lymph nodes and bone marrow were obliterated by neoplastic cells. The diagnosis of erythremic myelosis was given by clinical, laboratorial and pathological findings.

Key words: leukemia, DiGuglielmo's syndrome, anemia, myelogram, fine-needle aspiration cytology.

Neoplasmas hematopoéticos são doenças malignas, ou potencialmente malignas, envolvendo células da medula óssea (MO) (GRINDEM, 2000; VALLI et al., 2002). A denominação leucemia ocorre quando as células neoplásicas são observadas na $\mathrm{MO}$ e/ou no sangue circulante (HARVEY, 2001). A mielose eritrêmica é um tipo de leucemia, que envolve somente precursores eritróides, enquanto a eritroleucemia envolve tanto a linhagem eritróide quanto mielóide (MORRISON, 2001).

A mielose eritrêmica em animais e humanos (também denominada de síndrome de DiGuglielmo) caracteriza-se por um excesso de precursores eritróides na MO e que devem estar presentes no sangue periférico para caracterizar o diagnóstico (JACOBS et al., 2002). Essa enfermidade é considerada pouco frequente em gatos e raramente pode afetar cães, bovinos e suínos (COMAZZI et al., 2000; VARDIMAN

\footnotetext{
'Programa de Pós-graduação em Medicina Veterinária, Universidade Federal de Santa Maria (UFSM), Hospital Veterinário Universitário, prédio 97, sala 103, 97105-900, Santa Maria, RS, Brasil. E-mail: vetdanielimartins@yahoo.com.br. *Autor para correspondência.

"Universidade de Cruz Alta (UNICRUZ), Cruz Alta, RS, Brasil.

IIIDepartamento de Clínica de Pequenos Animais, UFSM, Santa Maria, RS, Brasil.

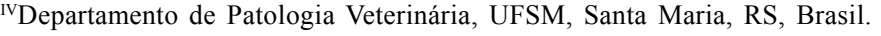


et al., 2002; VALLI et al., 2002). O presente trabalho relata o diagnóstico clínico-laboratorial e os achados anatomopatológicos de um gato com mielose eritrêmica.

Uma gata siamesa, castrada, um ano de idade, sem histórico de vacinação, apresentava mucosas intensamente pálidas, hiporexia há cerca de três semanas, emese há uma semana, emaciação e temperatura retal de $39,7^{\circ} \mathrm{C}$. Acentuada esplenomegalia foi notada à palpação. $\mathrm{O}$ animal estava sendo tratado há alguns dias com doxiciclina devido à suspeita de micoplasmose hemotrópica (Mycoplasma haemofelis), porém sem melhora no tratamento. Ultrassonografia, hemograma, contagem de reticulócitos, bioquímica sérica, mielograma, citologia aspirativa por agulha fina (CAAF) dos linfonodos poplíteos, pré-escapulares e submandibulares, testes sorológicos e exames histopatológicos foram requisitados para auxiliarem no diagnóstico.

A ultrassonografia confirmou aumento de volume esplênico e algumas áreas mais claras em sua superfície, sugerindo discreta fibrose capsular. Também foi observada grande quantidade de líquido livre no abdômen.

A proteína plasmática total foi de $8,7 \mathrm{~g} \mathrm{dL}^{-1}$, um pouco acima dos valores de referência locais $(6,0$ $\left.8,0 \mathrm{~g} \mathrm{dL}^{-1}\right)$, que pode ser um indício de hemoconcentração devido à desidratação causada pela emese. Os sinais de desidratação evidenciados pela paciente incluíam mucosas moderadamente secas e olhos profundos. Assim, os valores hematimétricos da paciente poderiam estar ainda mais baixos do que se encontravam, pois a desidratação poderia concentrar os componentes celulares do sangue, provocando uma falsa elevação em seus valores.

No hemograma, foi observada acentuada anemia ( $7 \%$ de hematócrito e hemoglobina de $\left.2,4 \mathrm{~g} \mathrm{dL}^{-1}\right)$, classificando-a como macrocítica normocrômica, com contagem de reticulócitos agregados abaixo de 60.000 $\mu \mathrm{L}^{-1}\left(1.200 \mu \mathrm{L}^{-1}\right)$. A anemia foi classificada como arregenerativa, o que em gatos é uma condição mais grave que em cães, já que o tempo médio de vida dos eritrócitos em felinos é bem menor se comparada aos caninos, 70 dias e 120 dias, respectivamente. Os leucócitos totais estavam dentro da normalidade para a espécie $\left(9.900 \mu \mathrm{L}^{-1}\right)$, bem como os valores da contagem diferencial (WEISS, 2000). As plaquetas estavam normais quanto a sua quantidade $\left(198.000 \mathrm{~mL}^{-1}\right)$ e morfologia (MORRISON, 2001).

Um grande número de células eritróides imaturas (metarrubrícitos, rubrícitos, rubriblastos e megaloblastos atípicos) foi notado no esfregaço sanguíneo. No entanto, não foram observadas policromasia e reticulocitose. A presença isolada de células eritróides imaturas sem reticulócitos no sangue circulante não é considerada um sinal de regeneração (WEISS, 2000; MORRISON, 2001). A pesquisa para hemoparasitas, realizada por meio de esfregaço sanguíneo, foi negativa. Os exames bioquímicos séricos para avaliação da função renal e hepática estavam dentro da normalidade.

Para se realizar diagnósticos de neoplasmas hematopoéticos é imprescindível a análise conjunta do sangue periférico e dos precursores hematopoéticos medulares (MORRISON, 2001; MUÑOZ, 2005). Devido às alterações observadas no hemograma do animal, requisitou-se a punção medular para realização do mielograma (VARDIMAN et al., 2002), que revelou acentuada predominância da população eritrocitária (acima de 85\%) sobre a mielóide. Foi evidenciada uma desordem mieloproliferativa relacionada à linhagem eritrocitária. A citologia da $\mathrm{MO}$ demonstrou intensa proliferação de células da linhagem eritróide (hiperplasia eritróide), muitas com aparência atípica, com características marcantes de malignidade como fragilidade celular e nucléolos múltiplos e evidentes, além de núcleos fragmentados. Também foi possível verificar a presença considerável de megacariócitos displásicos. Devido à hiperplasia eritróide, a proporção da série mielóide ficou prejudicada. Contudo, tal alteração não afetou o número de precursores mielóides na MO, pois foi evidenciado no sangue circulante um número de leucócitos adequado para a espécie.

Realizou-se a CAAF dos linfonodos poplíteos, pré-escapulares e submandibulares que se encontravam moderadamente aumentados. A CAAF, como primeiro método de investigação na linfoadenomegalia, permitiu a visualização de células eritróides neoplásicas nestes locais, demonstrando assim a possibilidade de colonização de células neoplásicas eritróides para outros órgãos além da MO.

A sorologia pelo método ELISA foi negativa para os vírus da imunodeficiência felina (FIV) e leucemia felina (FeLV). Vários autores atribuem o vírus da leucemia felina na patogênese da mielose eritrêmica (COMAZZI et al., 2000; MUÑOZ, 2005). No entanto, tal fato suscita a suspeita de que esse não seja o único mecanismo de produção da doença nos gatos.

Dessa maneira, a paciente foi diagnosticada clínico-laboratorialmente com mielose eritrêmica e o tratamento de suporte foi instituído (transfusão sanguínea, fluidoterapia, vitaminas do complexo B, antiemético, antitérmico, corticóide e nutrição enteral). Durante esse período, foi realizada a mensuração do hematócrito, que demonstrou queda gradativa cinco dias após a transfusão sanguínea. Após 12 dias do início da terapia medicamentosa, além das mucosas 
pálidas e febre, também havia discreta dispnéia e acentuada letargia. Assim, devido à falta de resposta ao tratamento e à deterioração do quadro clínico, a gata foi submetida à eutanásia e encaminhada ao Laboratório de Patologia.

$\mathrm{Na}$ necropsia, o animal estava caquético, com mucosas acentuadamente pálidas e sangue fluido e róseo. Havia cerca de $100 \mathrm{ml}$ de líquido amarelo e discretamente turvo no abdômen. Havia também marcada esplenomegalia com leve fibrose capsular (Figura 1A). O fígado estava moderadamente pálido, firme e recoberto por películas de fibrina. A MO dos ossos longos era difusamente vermelho-clara (Figura 1B), incluindo tanto epífises quanto diáfises. É interessante salientar que esse achado macroscópico pode indicar a infiltração da medula ativa na área onde deveria estar contida a medula amarela, pois se tratava de um animal adulto.

Os esfregaços citológicos do baço e da $\mathrm{MO}$ revelaram moderada quantidade de células blásticas da série vermelha $(>30 \%)$, acentuada anisocitose e anisocariose e 1 a 3 nucléolos grandes e pleomórficos/ célula (Figura 1C). A grande maioria das células ( $>90 \%$ ) era constituída por rubrícitos, metarrubrícitos e rubriblastos atípicos, com acentuado pleomorfismo, rubrícitos megaloblastóides, células binucleadas, assincronismo núcleo:citoplasma e megacariócitos displásicos. Ao exame histopatológico da MO e baço,

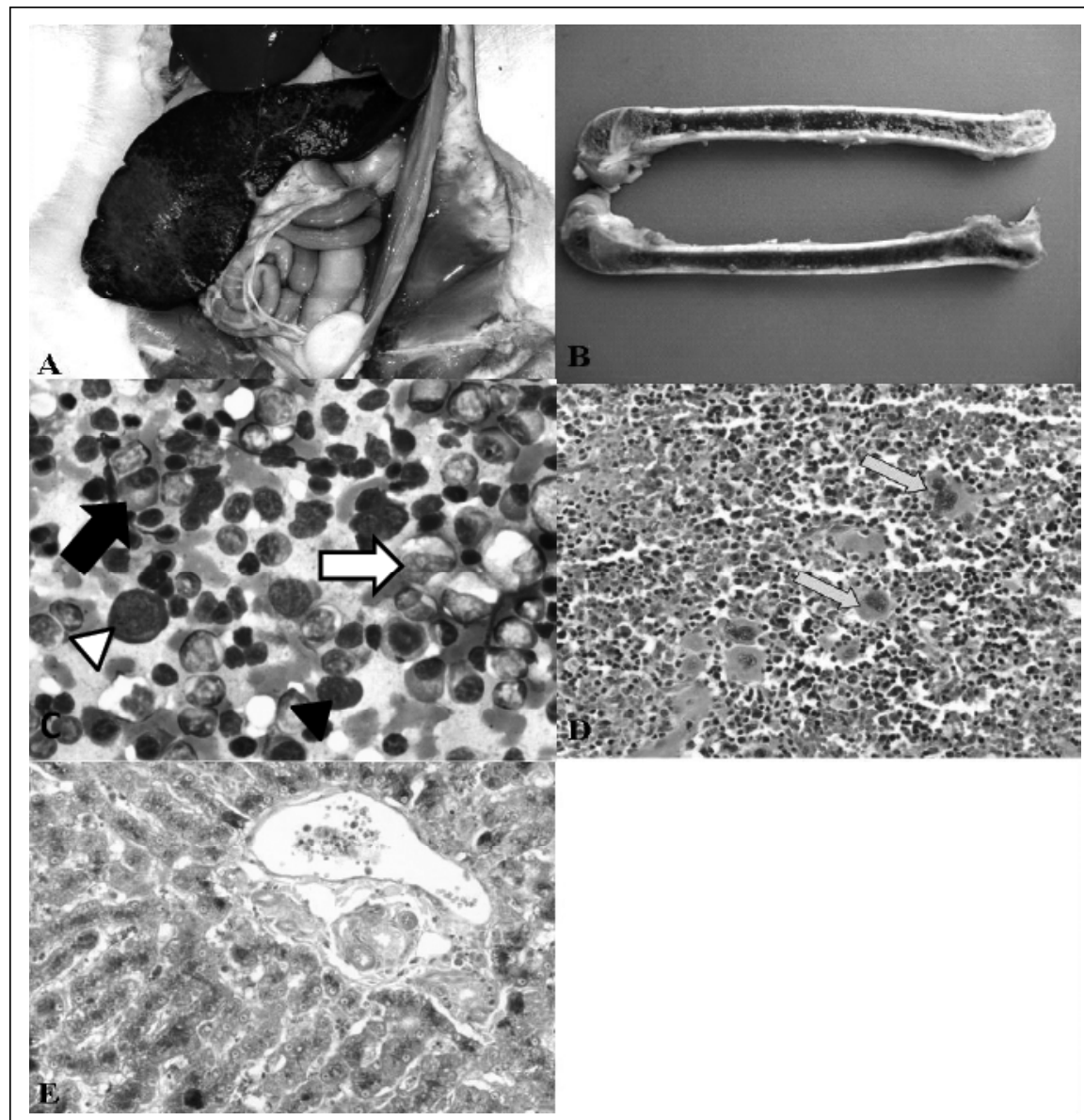

Figura 1 - Mielose eritrêmica, felino, Siamês, fêmea, um ano de idade. A) Acentuada esplenomegalia com fibrose capsular discreta. Os órgãos internos estão moderadamente pálidos. B) Medula óssea acentuadamente vermelho-clara, encontrada inclusive ao longo da diáfise, indicando haver acentuada hiperplasia e provável invasão da medula óssea amarela. C) Acentuada proliferação de rubrícitos (cabeça de seta preta), metarrubrícitos (seta preta), rubriblastos atípicos (seta branca) e rubrícitos megaloblastóides (cabeça de seta branca) na medula óssea (Panótico rápido, aumento de 400x. D). Infiltração acentuada de precursores eritróides obliterando toda arquitetura do baço, com múltiplos megacariócitos displásicos (setas) (Hematoxilina-eosina, aumento de 200x. E). Acentuada quantidade de pigmento azul (hemossiderina) no interior de hepatócitos. Azul da Prússia, aumento de 200x. 
notou-se infiltração de células neoplásicas nesses órgãos. Megacariócitos displásicos foram encontrados em grande quantidade, distribuídos difusamente ou em extensos agregados na MO (Figura 1D). O fígado apresentava acentuada hemossiderose (Figura 1E), com bilestase discreta e hematopoese extramedular periportal moderada.

Os achados anatomopatológicos ratificaram o diagnóstico clínico-laboratorial de mielose eritrêmica. A grande quantidade de precursores eritróides morfologicamente alterados no sangue e na MO é típica da doença (JACOBS et al., 2002). No caso dos precursores eritróides, pode haver a progressão de mielose eritrêmica para eritroleucemia ou para leucemia mieloblástica aguda (HARVEY et al., 1978; GRINDEM, 2000; MORRISON, 2001). Nesse caso, a doença não se apresentou com uma disseminação plena, pois, apesar da proporção de precursores mielóides estarem baixos na $\mathrm{MO}$ devido à hiperplasia eritróide, esses não se apresentavam morfologicamente alterados. Ainda, a doença também não havia afetado o número e a morfologia dos leucócitos presentes na circulação sanguínea.

A acentuada anemia arregenerativa do felino espelhou a gravidade do processo, sendo que esta é a principal característica clínica da doença em gatos. Apesar do aparente paradoxo da leucemia dos componentes sanguíneos, a produção de eritrócito maduro pelas células na MO é defeituosa. Esse fato é expresso, no presente relato, pela presença de células da linhagem eritróide imaturas, incluindo algumas com morfologia anormal (células megaloblastóides), lançadas na circulação periférica que não conseguem se diferenciar em reticulócitos e, posteriormente, em eritrócitos. Além disso, a proliferação desordenada das células neoplásicas compete por espaço com os precursores normais, levando à diminuição da eritropoese eficaz. A esse processo denomina-se mieloptise neoplásica (JACOBS et al., 2002).

Esplenomegalia, hepatomegalia e linfadenomegalia puderam ser encontradas e ocorreram pela infiltração de células neoplásicas no baço, fígado e linfonodos, respectivamente (COMAZZI et al., 2000). $\mathrm{O}$ acúmulo de líquido peritoneal geralmente não é descrito e, provavelmente, se deve à hipertensão hiliar esplênica. A hepatoesplenomegalia pode refletir a ativação do sistema mononuclear fagocítico, existência de hemólise extravascular e hematopoese extramedular (DAY, 1999). No entanto, atipia celular na MO e no sangue, além de megacariócitos displásicos, estão presentes em grande quantidade apenas na mielose eritrêmica e são características importantes no diagnóstico diferencial (GRINDEM, 2000). Contudo, as enzimas hepáticas mensuradas não foram afetadas, não refletindo o real estado do órgão.

A infecção por Mycoplasma haemofelis pode ocorrer concomitantemente, mas deve ser reconhecida como achado incidental, especialmente se houver ausência de policromasia (VALLI et al., 2002). Apesar de esse hemoparasita provavelmente não estar presente neste caso, sua presença deve ser encarada com cautela, visto que o Mycoplasma haemofelis pode ser um fator agravante da doença, especialmente em um animal debilitado.

O prognóstico da mielose eritrêmica é desfavorável e a doença é geralmente fatal (MORRISON, 2001; JACOBS et al., 2002). O presente felino apresentou resposta inadequada ao tratamento e piora gradativa do quadro clínico, prejudicando seu bem-estar.

A prática da punção medular é imprescindível no diagnóstico da doença (MUÑOZ, 2005), como visto neste relato. Histoquímica, citoquímica e imunofenotipagem também podem ser utilizados (VARDIMAN et al., 2002) para auxiliar o diagnóstico clínico-laboratorial.

Os achados clínicos, laboratoriais e anatomopatológicos permitiram concluir que o caso tratava-se de mielose eritrêmica, constituindo-se em ferramentas importantes para o diagnóstico da neoplasia, quando utilizados em conjunto. Dessa forma, é importante que o médico veterinário esteja atento ao aparecimento dessa doença, já que seu prognóstico é desfavorável.

\section{REFERÊNCIAS}

COMAZZI, S. et al. Erythremic myelosis (AML6Er) in a cat. Journal of Feline Medicine and Surgery, v.2, p.213215, 2000. Disponível em: <http://www.sciencedirect.com/ science?_ob=MImg\&_imagekey=B6WJC-45F4WW5-7$1 \&$ _cdi $=6875 \&$ \&user $=687358 \&$ \& pii $=$ S 1098612 X00901013\&_o rig $=$ search\&_coverDate $=12 \% 2 \mathrm{~F} 31 \% 2 \mathrm{~F} 2000 \&$ sk $=99997999$ $5 \&$ view $=\mathrm{c} \& w \mathrm{w}$ chp $=\mathrm{dGLzVzzzSkzS \& md5}=\mathrm{dbc} 12 \mathrm{e} 9 \mathrm{~d} 5 \mathrm{e} 6642 \mathrm{~b} 1 \mathrm{bd}$ 4 fe 5725cbf1236\&ie $=/$ sdarticle.pdf $>$. Acesso em: 09 out. 2009. doi: $10.1053 / \mathrm{jfms} .2000 .0101$.

DAY, M.J. Antigen specificity in canine autoimmune haemolytic anaemia. Veterinary Immunology and Immunopathology, v.69, p.215-244, 1999. Disponível em: <http://www.sciencedirect.com/ science?_ob=MImg\&_imagekey=B6TD5-3XF07MKD1\&_cdi $=5189 \&$ \&user $=687358 \&$ \& pii $=\mathrm{S} 0165242799000550 \&$ or ig =search\&_coverDate $=08 \% 2 \mathrm{~F} 02 \% 2 \mathrm{~F} 1999 \&$ sk $=999309997 \& \mathrm{vie}$

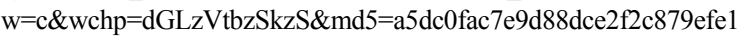
ec39\&ie=/sdarticle.pdf $>$. Acesso em: 09 out. 2009. doi:10.1016/ S0165-2427(99)00055-0.

GRINDEM, C.B. Hematologic/hematopoietic neoplasia. In: FELDMAN, B.F. et al. Veterinary hematology. 5.ed. Maryland: Lippincott Williams \& Wilkins, 2000. Section X, p.671-764. 
HARVEY, J.W. et al. Feline myeloproliferative disease changing manifestations in the peripheral blood. Veterinary Pathology, v.15, p.437-448, 1978. Disponível em: <http:// vet.sagepub.com/content/15/4/437.full.pdf + html $>$. Acesso em: 12 out. 2009. doi: 10.1177/030098587801500401.

HARVEY, J.W. Atlas of veterinary hematology: blood and bone marrow hematology. Philadelphia: Saunders, 2001. $228 \mathrm{p}$.

JACOBS, R.M. et al. Tumors of the hemolymphatic system. In: MEUTEN D.J. Tumors in domestic animals. 4. ed. Iowa: Iowa State, 2002. p.199-244.

MORRISON, J.A. Erythremic myelosis. Compendium on Continuing Education for the Practicing Veterinarian, v.23, p.880-885, 2001. Disponível em: $<$ http://www.veterinarytherapeutics.com/Media/
PublicationsArticle/PV_23_10_880.pdf $>$. Acesso em: 10 out. 2009.

MUÑOZ, L. Neoplasias hematopoyéticas en 10 gatos positivos al virus leucemia felina. Archivos de Medicina Veterinária, v.37, p.71-76, 2005.

VARDIMAN, J.W. et al. The World Health Organization (WHO) classification of the myeloid neoplasms. Blood, v.100, p.2292-2302, 2002.

VALLI, V.E. et al. Histological classification of hematopoietic tumors of domestic animals. Washington, AFIP-WHO, 2002. 190p. (Second Series, v.VIII).

WEISS, D.J. The erythrocytes. In: FELDMAN, B.F. et al. Veterinary hematology. 5.ed. Maryland: Lippincott Williams \& Wilkins, 2000. Section III, p.671-764. 